\title{
Análise da implementação dos institutos federais de educação no Piauí: escolha de municípios e cursos
}

\author{
José Tavares da Silva Neto \\ Instituto Brasileiro de Geografia e Estatística (IBGE) \\ Guiomar de Oliveira Passos \\ Universidade Federal do Piauí (UFPI)
}

Examina-se o processo de expansão da Rede Federal de Educação Profissional, Científica e Tecnológica no Estado do Piauí, de 2005 a 2011. Investiga-se a escolha dos municípios beneficiados com a implantação de campi e dos cursos ofertados pelos mesmos, inquirindo-se sobre a adequação do processo de expansão da Rede Federal de Educação Profissional e Tecnológica no Piauí às diretrizes governamentais postas para a mesma, no que concerne à distribuição das unidades de ensino pelo território piauiense e à escolha dos cursos ofertados. Procede-se uma análise de política pública na fase de implementação, segundo o ciclo de vida da mesma, examinando sua engenharia institucional e os traços constitutivos dos programas dela decorrentes, analisando suas escolhas, verificando se essas observaram as diretrizes e intenções estabelecidas pelo formulador. Verificou-se que as escolhas realizadas, em alguns momentos, distanciaram-se do marco normativo, embora não colidindo na totalidade com o mesmo; em outros momentos, aproximam-se dele, demonstrando a persecução do implementador às diretrizes definidas.

Palavras-chave: administração estadual, administração da educação, ensino superior, capacitação profissional, estudo de caso.

Artigo submetido em março de 2014. Versão final em agosto de 2014. 
Análisis de la expansión de la Red Federal de Educación Profesional, Ciencia y Tecnología en el estado de Piauí: municipios y cursos

Examina el proceso de expansión de la Red Federal de Educación Profesional, Ciencia y Tecnología en el estado de Piauí, de 2005 a 2011. Investiga la elección de los municipios se benefician de la implementación de los campus y los cursos ofrecidos por ellos, preguntando acerca de la adecuación de la expansión de la red federal de proceso de la educación profesional y tecnológica en el Piauí poner a las mismas directrices del gobierno , como se refiere a la distribución de las unidades didácticas de Piauí y la elección de los cursos ofrecidos. Es un análisis de las políticas públicas en la fase de ejecución, según el ciclo de vida de la misma, examinando su ingeniería institucional y rasgos que constituyen sus programas derivados, analizando sus opciones comprobando si éstos observaron las directrices y las intenciones establecidas por el formulador. Se encontró que las decisiones tomadas, en unos momentos, se distanciaron del marco normativo, aunque no chocar en su totalidad con la misma; en el otro, acercándose a él, lo que demuestra la persecución del implementador para establecer directrices.

Palabras clave: comunidades autónomas, gestión educativa, educación superior, capacitación profesional, estudio de caso

Analyzing the process of expansion of the Federal Network of Professional Education, Science and Technology in the state of Piauí (Brazil): the choice of municipalities and the courses

This paper examines the process of expansion of the Federal Network of Professional Education, Science and Technology in the state of Piauí, from 2005 to 2011 . We investigate the choice of municipalities benefited from the deployment of campuses and the courses offered by them. We inquire the adequacy of the processes to expand the federal network of professional and technological education in Piauí to the guidelines set by the federal government, regarding the distribution of teaching units in territory of Piaui and the choice of the courses offered. An analysis of public policy in the implementation phase was conducted, according to the life cycle of it, examining its institutional engineering and the constituent features of its programs, analyzing its choices by checking whether the intentions and guidelines established by the formulator were considered. It was found that the choices made in some moments differed from the normative framework, though not entirely colliding with it, while others approached it, demonstrating the pursuit of the implementer to follow guidelines.

Keywords: state government, educational management, higher education, professional qualification courses, case study 


\section{Introdução}

Este trabalho tem por objeto a expansão das instituições federais de educação profissional, científica e tecnológica empreendida pelo Ministério da Educação, a partir de 2005 até 2011, no Piauí. Segundo dados do Instituto Nacional de Estudos e Pesquisas Educacionais Anísio Teixeira (Inep), tais estabelecimentos de ensino, que em 2002 totalizavam 138 em nível nacional, passam a 146 em 2005, com o lançamento da primeira fase do Plano de Expansão da Rede Federal de Educação Profissional e Tecnológica, determinado pela Lei $n$ o 11.195/2005, e chegam a 252 em 2010, com a segunda fase do plano.

Investiga-se neste trabalho a escolha dos municípios beneficiados com a implantação de campi e dos cursos ofertados pelos mesmos, examinando a definição de municípios e cursos. Pergunta-se: qual o status dos municípios beneficiados, isto é, eles são cidades-polo, como previsto no Plano Plurianual 2008-2011 e na Chamada Pública MEC/Setec no 001/2007, e qual sua área de influência? Os cursos contemplam que eixos tecnológicos e que setores da economia? Esses setores são os mais importantes para a região? São os que oferecem mais possibilidades de transformação da realidade socioeconômica?

As questões propostas têm por objetivo examinar, em primeiro lugar, a adequação do processo de expansão da Rede Federal de Educação Profissional e Tecnológica às diretrizes governamentais definidas para a mesma, no que concerne à distribuição das unidades de ensino pelo território piauiense. A expansão da rede, consoante a Secretaria de Educação Profissional e Tecnológica, deve "orientar-se, preferencialmente, para as periferias de grandes centros urbanos e em municípios interioranos, distantes de centros urbanos", com a intenção de "implantar uma escola técnica em cada cidade-polo do País" (BRASIL, 2006j, p. 2), estratégia definida no PPA 2008-2011 (BRASIL, 2007a), para a qual o objetivo posto é "vincular a oferta pública de formação profissional às estratégias de desenvolvimento socioeconômico sustentável", a ser viabilizado pelo "fortalecimento da atividade produtiva e da educação, ciência e tecnologia nas principais mesorregiões atualmente definidas" (BRASIL, 2007b, p. 1).

Em segundo lugar, pretende-se analisar a efetivação da estratégia para a atuação dos institutos federais de educação, que evidencie a articulação entre educação, desenvolvimento e territorialidade, definida pelo Plano de Desenvolvimento da Educação (BRASIL, 2007c) e no inciso IV do art. 6ㅇ da Lei no 11.892/2008, que estabelece as seguintes finalidades e características dos institutos:

Orientar sua oferta formativa em benefício da consolidação e fortalecimento dos arranjos produtivos, sociais e culturais locais, identificados com base no mapeamento das potencialidades de desenvolvimento socioeconômico e cultural no âmbito de atuação do Instituto Federal (BRASIL, 2008). 
Adicionalmente, procede-se à construção de um quadro comparativo entre o que foi estabelecido no planejamento institucional de cursos do Instituto Federal do Piauí (IFPI) e o que foi efetivamente realizado, buscando evidenciar o marco de intenções institucionais e os resultados alcançados na implementação.

Trata-se de analisar a política, examinando sua engenharia institucional e os traços constitutivos dos programas dela decorrentes, analisando suas escolhas, procurando construir, na expressão de Serafim e Dias (2011, p. 322), um "conjunto de observações de caráter descritivo e explicativo" que evidenciem as escolhas, verificando, também, se essas observaram as diretrizes e intenções estabelecidas pelo formulador. Trata-se, por conseguinte, de analisar a política depois de formulada, examinando a "discricionariedade por parte dos implementadores" (SERAFIM; DIAS, 2011, p. 332), para adequá-la à realidade.

A análise representa a possibilidade de verificação das decisões e escolhas tomadas na fase de implementação que condicionam, positiva ou negativamente, os efeitos esperados para a política no momento de sua formulação. Em outras palavras, busca-se verificar se, na fase de implementação da política pública, "durante a qual se geram atos e feitos", observou-se "o marco normativo de intenções, de textos ou de discursos" (SERAFIM; DIAS, 2011, p. 332) dos formuladores da política.

Por conseguinte, no estudo aqui proposto, a análise recairá sobre a fase de implementação da política pública, compreendida "como processo autônomo onde decisões cruciais são tomadas" e não apenas executadas, tendo o implementador um grande espaço de discricionariedade, a tal ponto que é "variável decisiva do seu sucesso" (Silva; Melo, 2000, p. 10-11).

O trabalho divide-se em dois momentos: no primeiro, analisa-se a distribuição dos campi pelas mesorregiões do território piauiense, verificando a adequação às diretrizes programadas para a expansão, a condição de cidade-polo, e o status dos municípios contemplados na rede urbana piauiense. No segundo, examinase a oferta de cursos, as modalidades, eixos tecnológicos, setores da economia e atividades produtivas contemplados, bem como seus espaços na oferta.

\section{A escolha dos municípios para instalação de campus}

O processo de expansão da Rede Federal de Educação, Ciência e Tecnologia, Fases I e II, resultou na instalação de nove campi no Estado do Piauí, distribuídos por sete territórios de desenvolvimento, entre os 11 estabelecidos na Lei Complementar no 87, de 22 de agosto de 2007 (PIAUí, 2007). Os contemplados foram: Planície Litorânea, dos Cocais, do Entre Rios, do Vale do Rio Guaribas, dos Tabuleiros do Alto Parnaíba, da Serra da Capivara e da Chapada das Mangabeiras. Registre-se que, no Território do Vale do Rio Piauí e Itaueiras, já havia um campus desde 1994. 
Em todos esses sete territórios beneficiados foi instalada uma unidade, exceto nos Territórios do Vale do Rio Guaribas e do Entre Rios, que ganharam duas unidades: no primeiro, os campi de Picos e Paulistana; no segundo, ao já existente campus Teresina-Central, acrescentaram-se os campi de Teresina Zona-Sul e de Angical.

O Território do Entre Rios, o de maior população e Produto Interno Bruto (PIB) entre os territórios do estado, e com mais demanda e renda, passa a contar com três campi; e o Território do Vale Rio Guaribas, o segundo em população e Produto Interno Bruto, dois campi.

De acordo com o PIB registrado pelo IBGE em 2010, os territórios não contemplados - Vale do Sambito, Vale do Rio Canindé e dos Carnaubais - são as menores economias entre os territórios de desenvolvimento (respectivamente, 11a, 10 ${ }^{a}$ e $8^{a}$ ) e também estão entre os menores contingentes populacionais (respectivamente, 10, 9을 7으).

Essa distribuição abrange as quatro macrorregiões definidas na Lei Complementar no 87/2007: Litoral - com 1 unidade, Meio Norte - 3 unidades, Semiárido - 3 unidades e Cerrados - com 2 unidades. Ou as quatro mesorregiões definidas pelo IBGE (2013) para o Estado do Piauí: Centro-Norte Piauiense, Norte Piauiense, Sudeste Piauiense e Sudoeste Piauiense. Desse modo, está de acordo com o critério posto pela Chamada Pública MEC/Setec no 001/2007, de "cobertura do maior número possível de mesorregiões em cada Unidade da Federação" (BRASIL, 2007b, p. 1).

Os municípios escolhidos, suas respectivas posições e área de influência são descritos na Tabela 1.

A distribuição dos campi pelos centros de gestão do território, conforme o IBGE (2008), está apresentada na Figura 1.

Verifica-se que as cidades contempladas têm posições distintas na hierarquia definida pelo IBGE, mostrando que a definição feita no Anexo I da Chamada Pública MEC/Setec no 001/2007 (BRASIL, 2007c) não procedeu de modo a distribuir os campi entre cidades com o mesmo status. Assim, ao tempo em que contemplava desde aquela com o maior status no estado - Capital Regional A - até a de menor - Centro Local -, dava tratamento desigual às com o mesmo status, vez que, enquanto uma foi contemplada, outras foram excluídas, quando outra de menor status recebeu a unidade de ensino. 
Tabela 1: Municípios: status $\mathrm{x}$ área de influência x existência de escola profissional

\begin{tabular}{c|c|c|c}
\hline Municípios & $\begin{array}{c}\text { Status conferido pelo } \\
\text { IBGE }\end{array}$ & $\begin{array}{c}\text { No de municípios } \\
\text { sob influência (IBGE) }\end{array}$ & $\begin{array}{c}\text { Existência de escola de } \\
\text { ensino profissional }\end{array}$ \\
\hline Teresina & Capital Regional A & $\begin{array}{c}271 \\
(224 \text { no Estado do PI } \\
+47 \text { no MA })\end{array}$ & $\begin{array}{c}\text { Campus Teresina-Central/ } \\
\text { IFPI }\end{array}$ \\
\hline Parnaíba & Centro Sub-regional A & 16 & 00 \\
\hline Picos & Centro Sub-regional A & $\begin{array}{c}(10 \text { no estado do PI } \\
+6 \text { no MA) }\end{array}$ & 01 \\
\hline $\begin{array}{c}\text { São Raimundo } \\
\text { Nonato }\end{array}$ & Centro Sub-regional B & 37 & 00 \\
\hline Corrente & Centro de Zona A & 12 & 01 \\
\hline Piripiri & Centro de Zona A & 07 & 01 \\
\hline Paulistana & Centro de Zona B & 05 & 00 \\
\hline Uruçuí & Centro de Zona B & 04 & 00 \\
\hline Angical & Centro Local & 00 & 01 \\
\hline
\end{tabular}

Fonte: Instituto Brasileiro de Geografia e Estatística (IBGE, 2008), Ministério da Educação (BRASIL, 2013a-i)

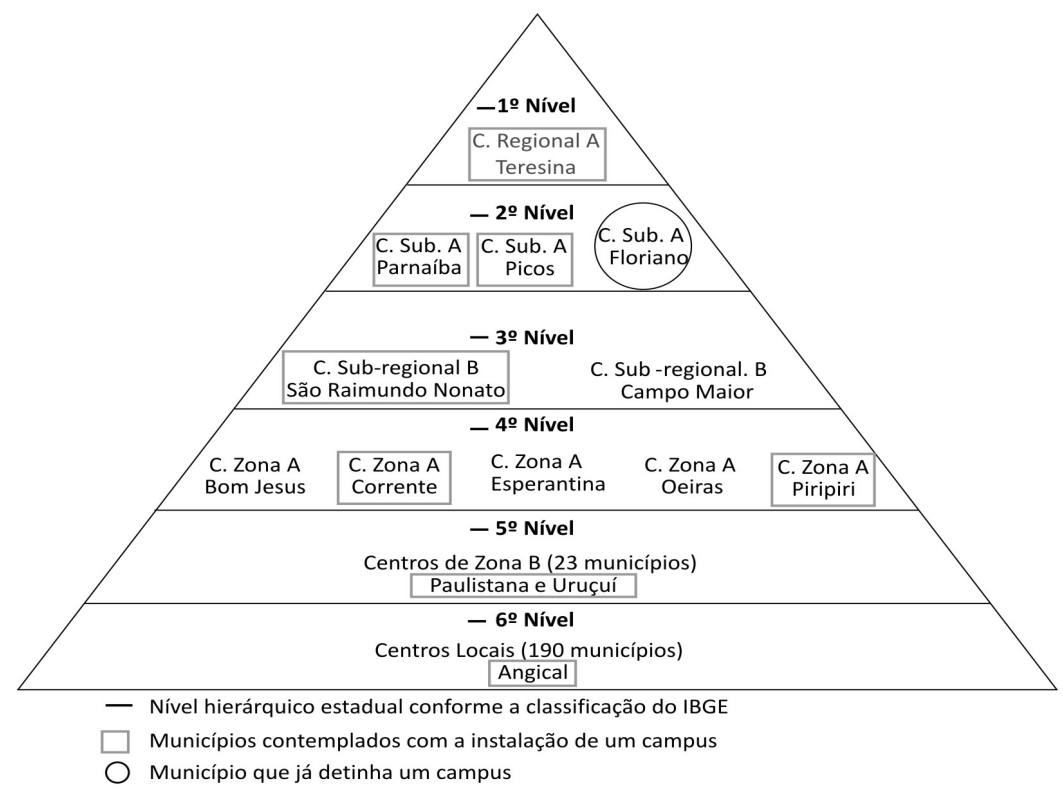

Fonte: Instituto Brasileiro de Geografia e Estatística (IBGE, 2008).

Figura 1: Distribuição dos campi pelos centros de gestão do território 
É verdade que todos aqueles municípios que estão na primeira e segunda posições foram contemplados, mas, enquanto foram instaladas unidades em cidades situadas na quarta, quinta ou sexta posições, outras mais bem situadas na hierarquia não receberam nenhuma unidade. Essa é a situação de Campo Maior que está no terceiro nível hierárquico, mas não recebeu um único campus, enquanto Piripiri e Corrente, ambas no quarto nível, tiveram sua escola. Ou ainda a situação de Oeiras, Bom Jesus e Esperantina, que, além de receberem tratamento diferenciado em relação a Piripiri e Corrente, no seu mesmo nível hierárquico, como que foram preteridas diante de Paulistana e Uruçuí, que têm raio de influência menor.

Chama a atenção não apenas a escolha de Angical, que tem área de influência restrita e recebeu uma escola, enquanto outros municípios com maiores possibilidades de abrangência foram preteridos, mas também a justificativa do IFPI para essa instalação. Segundo o mesmo, "verifica-se uma forte heterogeneidade e assimetria na distribuição regional dessas estruturas e dos serviços disponíveis, sobretudo ao se analisar a situação do município de Teresina e sua relação com os demais municípios" (IFPI, 2009, p. 52-53). Afirma ainda que, "tendo em vista essas realidades", se propõe "através do campus de Angical a mudar essa realidade, objetivando intervir no desenvolvimento da cidade de Angical e dos municípios circunvizinhos".

A área de influência parece não ter sido critério de escolha, haja vista as diferenças entre os escolhidos (em termos de número de municípios sob sua influência) e, principalmente, o fato de municípios com grande área de influência terem sido preteridos, como, por exemplo, Campo Maior, cuja área envolve 12 municípios, enquanto Piripiri, com apenas 7 municípios de influência recebeu um campus.

A definição da Chamada Pública MEC/Setec no 001/2007 (BRASIL, 2007b), então, contraria ou se afasta do previsto no PPA 2008-2011 (BRASIL, 2007a), talvez em face da não definição do que seja uma cidade-polo, ou talvez seja a contribuição do IFPI ao desenvolvimento regional, investindo em infraestrutura para que os municípios mais pobres superem o atraso, em particular no que se refere à ampliação das oportunidades de escolarização profissional e superior e, de certo modo, à fixação das populações nessas regiões.

A essas escolhas não se pode desconsiderar a possibilidade, como previsto na Chamada Pública (BRASIL, 2007b, p. 2), de "aproveitamento de infraestruturas físicas existentes" e, principalmente, de formação de parcerias, em particular com os municípios com a oferta de terreno, sendo inclusive critério para a definição de prioridades. Ademais, a continuidade do processo de expansão pode dar resposta a análises que pontuem discordâncias sobre as escolhas feitas por meio da implantação de novos campi. 
De qualquer modo, essas análises evidenciam o que ocorre na fase de implementação de uma política pública, que não só pode redefinir seus objetivos a partir das negociações e modos de adesão dos implementadores, como também pode viabilizar espaço para ações distintas das previstas, quando é amplo o espaço de discricionariedade dos agentes, seja por conta da imprecisão do conceito cidadepolo, ou por conta das múltiplas finalidades da expansão.

O exame da escolha dos cursos, a seguir, ajudará na compreensão dessas escolhas.

\section{A escolha dos cursos}

Os nove campi instalados ofertam 122 cursos, 28 a mais do que a meta estabelecida nos instrumentos de planejamento institucional, plano de desenvolvimento institucional (PDI) 2009-2013 (IFPI, 2009) e 2010-2014 (IFPI, 2010). Esses cursos estão distribuídos nas modalidades médio integrado, técnico subsequente/concomitante, educação de jovens e adultos, educação a distância e graduação (licenciaturas ou superior em tecnologia). Os 94 cursos planejados, por campus e modalidade, são os seguintes:

Tabela 2: Cursos planejados por campus e modalidade de ensino

\begin{tabular}{|c|c|c|c|c|c|c|c|}
\hline \multirow{2}{*}{ Municípios } & \multirow{2}{*}{$\begin{array}{c}\text { Técnico } \\
\text { Integrado }\end{array}$} & \multirow{2}{*}{$\begin{array}{l}\text { Técnico } \\
\text { Subse- } \\
\text { quente }\end{array}$} & \multirow{2}{*}{ PROEJA } & \multirow{2}{*}{ EAD } & \multicolumn{2}{|c|}{ Graduação } & \multirow{2}{*}{ Total } \\
\hline & & & & & Licenciatura & $\begin{array}{c}\text { Superior em } \\
\text { Tecnologia }\end{array}$ & \\
\hline Picos & 05 & 04 & 04 & 00 & 02 & 04 & $19^{*}$ \\
\hline Parnaíba & 03 & 04 & 01 & 00 & 02 & 01 & 11 \\
\hline Uruçuí & 02 & 02 & 02 & 00 & 03 & 01 & 10 \\
\hline $\begin{array}{l}\text { Teresina } \\
\text { Zona-Sul }\end{array}$ & 03 & 05 & 02 & 00 & 00 & 02 & 12 \\
\hline Corrente & 02 & 03 & 01 & 00 & 03 & 03 & 12 \\
\hline $\begin{array}{l}\text { São Raimundo } \\
\text { Nonato }\end{array}$ & 02 & 02 & 02 & 00 & 02 & 00 & 08 \\
\hline Piripiri & 02 & 02 & 01 & 00 & 02 & 00 & 07 \\
\hline Paulistana & 02 & 02 & 01 & 00 & 02 & 00 & 07 \\
\hline Angical & 02 & 02 & 02 & 00 & 02 & 00 & 08 \\
\hline TOTAL & 23 & 26 & 16 & 00 & 18 & 11 & 94 \\
\hline
\end{tabular}

Fonte: PDI 2009-2013 (IFPI, 2009); PDI 2010-2014 (IFPI, 2010)

* Além desses, foram previstos, nos Planos de Desenvolvimento (IFPI, 2009; IFPI, 2010), dois cursos de pósgraduação lato sensu (Banco de Dados de Ensino de Ciências). 
O ensino profissionalizante deteve $70 \%$ do total planejado, sendo $24 \%$ na modalidade integrado ao ensino médio, $28 \%$, na subsequente e $17 \%$ vinculados à educação de jovens e adultos. A maior frequência entre os profissionalizantes, era do ensino técnico subsequente. Já entre os cursos superiores, prevalecem os de licenciatura (19\%) e os tecnológicos (em 50 lugar, correspondendo a 12\%). Também foram previstos dois cursos de pós-graduação lato sensu (2,08\%) para o campus de Picos.

Os 122 cursos ofertados, por sua vez, por campus e modalidade, são os seguintes:

Tabela 3: Cursos ofertados por campus e modalidade

\begin{tabular}{|c|c|c|c|c|c|c|c|}
\hline \multirow{2}{*}{ Municípios } & \multirow{2}{*}{$\begin{array}{c}\text { Técnico } \\
\text { Integrado }\end{array}$} & \multirow{2}{*}{$\begin{array}{c}\text { Técnico } \\
\text { Subsequen- } \\
\text { te }\end{array}$} & \multirow{2}{*}{ PROEJA } & \multirow{2}{*}{ EAD } & \multicolumn{2}{|c|}{ Graduação } & \multirow{2}{*}{ Total } \\
\hline & & & & & $\begin{array}{l}\text { Licencia- } \\
\text { tura }\end{array}$ & $\begin{array}{c}\text { Superior em } \\
\text { Tecnologia }\end{array}$ & \\
\hline Picos & 04 & 04 & 05 & 08 & 02 & 00 & 23 \\
\hline Parnaíba & 04 & 05 & 01 & 06 & 02 & 00 & 18 \\
\hline Uruçuí & 02 & 02 & 00 & 05 & 01 & 00 & 10 \\
\hline $\begin{array}{l}\text { Teresina } \\
\text { Zona-Sul }\end{array}$ & 03 & 05 & 01 & 02 & 01 & 00 & 12 \\
\hline Corrente & 02 & 03 & 01 & 04 & 01 & 01 & 12 \\
\hline $\begin{array}{c}\text { São } \\
\text { R. Nonato }\end{array}$ & 02 & 04 & 00 & 05 & 01 & 01 & 13 \\
\hline Piripiri & 03 & 03 & 01 & 05 & 01 & 00 & 13 \\
\hline Paulistana & 02 & 02 & 00 & 05 & 00 & 00 & 09 \\
\hline Angical & 02 & 04 & 00 & 04 & 02 & 00 & 12 \\
\hline TOTAL & 24 & 32 & 09 & 44 & 11 & 02 & 122 \\
\hline
\end{tabular}

Fonte: Instituto Federal do Piauí (IFPI, 2013)

A oferta de cursos superiores é menor do que a planejada: de $31 \%$ do total, passou a representar $11 \%$, enquanto a de cursos profissionalizantes passou de $70 \%$ para $89 \%$. Nesses, como no planejado, o maior número foi dos técnicos subsequentes, agora com $62 \%$ do total, dos quais $36 \%$ na modalidade a distância, que, como se comprova acima, não constava no planejamento. O técnico integrado foi reduzido de $24 \%$ para $20 \%$. Os cursos na modalidade de educação de jovens e adultos, por sua vez, passaram de $17 \%$ para $7 \%$.

É verdade que os cursos técnicos integrados ao médio podem significar uma oportunidade de acesso ao ensino médio de qualidade, tratando-se de preparatório apenas para o ingresso na educação superior, como constatou Pereira (2012). Os campi de Picos e Parnaíba, por exemplo, alcançaram o 4ㅇ lugar entre as escolas do município e o 1 을 entre as escolas públicas no Exame Nacional de Ensino Médio de 2011(primeira edição da que participaram e o último divulgado por escola). Ter acesso a esse ensino médio de qualidade pode significar a garantia de continuidade 
dos estudos, já que as instituições estaduais, nessa avaliação, tiveram média inferior às melhores colocadas em até 250 pontos (BRASIL, 2013m).

Entre os cursos superiores, a maior oferta permaneceu nos cursos de licenciatura, que diminuíram a participação no total (19\% para 9\%), mas aumentaram entre os desse nível de ensino (de 62\% para $85 \%$ ). Já a graduação tecnológica ficou reduzida a $2 \%$ do total de oferecidos e a $15 \%$ entre os cursos de nível superior.

Assim, o acréscimo na oferta frente ao planejado ocorreu em cursos técnicos subsequentes na modalidade a distância; essa oferta, além de responder pelo aumento dos 28 cursos acrescidos ao total (de 94 para 122), ocupou quantitativamente os espaços deixados pela supressão dos cursos superiores.

Verifica-se, então, que a preocupação não era com a falta de acesso ao ensino médio, mas com a profissionalização. Por conseguinte, não foi a taxa de escolarização do ensino médio que norteou a escolha, mas talvez a carência de oportunidades de formação profissional.

Examina-se, a seguir, a distribuição dos cursos planejados e ofertados com os arranjos produtivos locais e os eixos tecnológicos:

Tabela 4: Cursos planejados $\mathrm{x}$ eixos tecnológicos

\begin{tabular}{|c|c|c|c|c|c|c|c|c|c|c|}
\hline Eixo Tecnológico & Picos & $\begin{array}{c}\text { Parnaí- } \\
\text { ba }\end{array}$ & Uruçuí & $\begin{array}{l}\text { Teresina } \\
\text { Zona-Sul }\end{array}$ & Corrente & $\begin{array}{l}\text { São R. } \\
\text { Nonato }\end{array}$ & Piripiri & $\begin{array}{l}\text { Paulis- } \\
\text { tana }\end{array}$ & $\begin{array}{l}\text { An- } \\
\text { gical }\end{array}$ & Total \\
\hline $\begin{array}{l}\text { Ambiente e } \\
\text { Saúde }\end{array}$ & & & 01 & & 02 & & & & & 03 \\
\hline $\begin{array}{l}\text { Controle e Pro- } \\
\text { cessos Industriais }\end{array}$ & 04 & 02 & & & & & & & & 06 \\
\hline Ensino & 02 & 02 & 03 & & 03 & 02 & 02 & 02 & 02 & 18 \\
\hline $\begin{array}{l}\text { Gestão e } \\
\text { Negócios }\end{array}$ & 04 & 01 & & & & & & & 03 & 08 \\
\hline $\begin{array}{l}\text { Informação e } \\
\text { Comunicação }\end{array}$ & 05 & 04 & & & 03 & 01 & 02 & 03 & 03 & 21 \\
\hline Infraestrutura & 02 & 02 & 01 & 05 & & & & & & 10 \\
\hline $\begin{array}{l}\text { Produção } \\
\text { Alimentícia }\end{array}$ & 01 & & 02 & 01 & & & & & & 04 \\
\hline $\begin{array}{l}\text { Produção } \\
\text { Cultural e Design }\end{array}$ & & & & 01 & & & & & & 01 \\
\hline $\begin{array}{l}\text { Produção } \\
\text { Industrial }\end{array}$ & 01 & & & 02 & & & 03 & & & 06 \\
\hline $\begin{array}{l}\text { Recursos } \\
\text { Naturais }\end{array}$ & & & 03 & & 04 & 01 & & 02 & & 10 \\
\hline $\begin{array}{l}\text { Turismo, Hospi- } \\
\text { talidade e Lazer }\end{array}$ & & & & 03 & & 04 & & & & 07 \\
\hline Total & 19 & 11 & 10 & 12 & 12 & 08 & 07 & 07 & 08 & 94 \\
\hline
\end{tabular}

Fonte: Catálogo Nacional de Cursos Técnicos (BRASIL, 2013j); Catálogo Nacional de Cursos Superiores em Tecnologia (BRASIL, 2013I) 
O eixo tecnológico Informação e Comunicação representa $22,3 \%$ do total de cursos planejados; o eixo Ensino, 19,1\%; o eixo tecnológico Infraestrutura, 10,6\%; o eixo tecnológico Recursos Naturais representa 10,6\%; o eixo Gestão e Negócios, 8,5\%; o eixo Turismo, Hospitalidade e Lazer, 7,4\%; o eixo Controle e Processos Industriais, 6,4\%; o eixo Produção Industrial, 6,4\%; o eixo Produção Alimentícia, 4,25\%; o eixo Ambiente e Saúde, 3,2\%; e o eixo Produção Cultural e Design, 1,06\%. Predomina, então, no planejamento, o eixo tecnológico, em duas modalidades: Informação e Comunicação e o eixo Ensino.

Na oferta, a distribuição entre os eixos tecnológicos é a seguinte:

\section{Tabela 5: Cursos ofertados x eixos tecnológicos}

\begin{tabular}{|c|c|c|c|c|c|c|c|c|c|c|}
\hline $\begin{array}{c}\text { Eixo } \\
\text { Tecnológico }\end{array}$ & Picos & $\begin{array}{c}\text { Parnaí- } \\
\text { ba }\end{array}$ & Uruçuí & $\begin{array}{l}\text { Teresina } \\
\text { Zona-Sul }\end{array}$ & $\begin{array}{c}\text { Corren- } \\
\text { te }\end{array}$ & $\begin{array}{l}\text { São R. } \\
\text { Nonato }\end{array}$ & Piripiri & $\begin{array}{c}\text { Pau- } \\
\text { lista- } \\
\text { na }\end{array}$ & $\begin{array}{l}\text { Angi- } \\
\text { cal }\end{array}$ & Total \\
\hline $\begin{array}{l}\text { Ambiente e } \\
\text { Saúde }\end{array}$ & 01 & & 01 & & 02 & 01 & 01 & 01 & 01 & 08 \\
\hline $\begin{array}{l}\text { Controle e } \\
\text { Processos } \\
\text { Industriais }\end{array}$ & 04 & 02 & & & & & & & & 06 \\
\hline Ensino & 02 & 02 & 01 & 01 & 01 & 01 & 01 & & 02 & 11 \\
\hline $\begin{array}{l}\text { Gestão e } \\
\text { Negócios }\end{array}$ & 05 & 04 & 02 & 01 & 02 & 02 & 07 & 02 & 05 & 30 \\
\hline $\begin{array}{l}\text { Informação e } \\
\text { Comunicação }\end{array}$ & 06 & 06 & 01 & 01 & 03 & 03 & 01 & 03 & 03 & 27 \\
\hline Infraestrutura & 04 & 02 & & 04 & & & & & & 10 \\
\hline $\begin{array}{l}\text { Produção } \\
\text { Alimentícia }\end{array}$ & & & 02 & 01 & & & & & 01 & 04 \\
\hline \multicolumn{11}{|l|}{$\begin{array}{c}\text { Produção } \\
\text { Cultural e } \\
\text { Design }\end{array}$} \\
\hline $\begin{array}{l}\text { Produção } \\
\text { Industrial }\end{array}$ & & & & 02 & & & 02 & & & 04 \\
\hline $\begin{array}{l}\text { Recursos } \\
\text { Naturais }\end{array}$ & & & 02 & & 03 & & & 02 & & 07 \\
\hline Segurança & 01 & 01 & 01 & & 01 & 01 & 01 & 01 & & 07 \\
\hline $\begin{array}{l}\text { Turismo, } \\
\text { Hospitalidade } \\
\text { e Lazer }\end{array}$ & & 01 & & 02 & & 05 & & & & 08 \\
\hline Total & 23 & 18 & 10 & 12 & 12 & 13 & 13 & 09 & 12 & 122 \\
\hline
\end{tabular}

Fonte: Catálogo Nacional de Cursos Técnicos (BRASIL, 2013j); Catálogo Nacional de Cursos Superiores em Tecnologia (BRASIL, 2013I)

O eixo tecnológico Gestão e Negócios detém 25,6\% do total de cursos ofertados; o eixo tecnológico Informação e Comunicação detém 22,1\%; o eixo Ensino, 9\%; o eixo tecnológico Infraestrutura, 8,2\%; o eixo tecnológico Ambiente e Saúde, 6,5\%; 
o eixo Turismo, Hospitalidade e Lazer, 6,5\%; o eixo Recursos Naturais, 5,7\%; o eixo Segurança, 5,7\%; o eixo Controle e Processos Industriais, 4,9\%; o eixo Produção Industrial, 3,3\%; e o eixo Produção Alimentícia, 3,3\%. O predomínio agora é do eixo tecnológico Gestão e Negócios e do eixo tecnológico Informação e Comunicação, que juntos representam quase a metade $(47,7 \%)$ dos cursos ofertados.

Esses dados permitem verificar o distanciamento entre o planejamento original e a oferta efetiva. No planejamento original, a área de Gestão e Negócios representava $8,5 \%$ do total, enquanto na oferta efetiva, passou a representar $25,6 \%$. A área de Ensino tem seu espaço reduzido (são suprimidos sete cursos, 39\% do planejado), a área de Turismo e Lazer tem sua oferta aumentada em um curso (14,3\%), e a área de Ambiente e Saúde, em cinco cursos (167\%).

Os eixos Controle e Processos Industriais, Infraestrutura e Produção Alimentícia ofertam o quantitativo de cursos planejado. Já o eixo Produção Industrial teve, em relação ao planejado, uma redução de dois cursos (33,3\%).

A área de Recursos Naturais teve seu espaço reduzido em números absolutos de 10 para 7 e, em relação ao total dos cursos, em 4,7\% (de 10,4\% para 5,7\%). A novidade é a oferta de cursos na área de Segurança, enquanto o eixo Produção Cultural e Design foi suprimido da oferta.

Os eixos tecnológicos planejados e ofertados voltam-se para os setores da economia da forma e quantitativos descritos na Tabela 6.

Verifica-se, entre o planejado e o ofertado, um aumento significativo de cursos voltados para o setor de serviços. São trinta e quatro cursos a mais do que o planejado, o que significa um aumento de 59,6\%. Quando do planejamento, o setor de serviços ocupava $61 \%$ do total dos cursos, já na oferta, passa a ocupar $74,6 \%$. Essa oferta volta-se para o principal setor da economia local e regional, o de serviços. Entre os municípios contemplados com a instalação de um campus, o percentual de participação do valor adicionado bruto, a preços correntes, do setor de serviços, com exceção do Município de Uruçuí, varia entre 73,22\%, em Angical do Piauí, e 83,2\%, em Picos. O Município de Uruçuí é o único cujo setor de serviços não lidera a repartição entre os setores na economia local.

Do setor de serviços, a área de Gestão e Negócios e a de Turismo e Lazer são apontadas pelo Plano de Ação para o Desenvolvimento Integrado da Bacia do Parnaíba (Planap) (BRASIL, 2006a-i) e PDIs (IFPI, 2009; IFPI, 2010) como atividades potenciais e consolidadas, na maior parte dos territórios e municípios onde se encontram instalados campi. No primeiro caso, entre outros, tem-se o turismo de negócios e de eventos, e os serviços de saúde, o comércio e os serviços públicos, em Teresina (Entre Rios); a prestação de serviços, vinculada ao turismo, e o comércio, em Parnaíba (Planície Litorânea); o comércio e a prestação de serviços, em Picos (Vale do Guaribas). No segundo, o turismo, no Território da Serra da Capivara 
(São Raimundo Nonato), no Território dos Cocais (Piripiri) e na Planície Litorânea (Parnaíba); e o turismo de negócios e eventos no Território Entre Rios (Teresina).

Tabela 6: Eixos tecnológicos por setores da economia: planejados $\mathrm{x}$ ofertados

\begin{tabular}{|c|c|c|c|c|c|c|}
\hline \multirow[t]{2}{*}{ Eixo Tecnológico } & \multicolumn{2}{|c|}{ Agropecuária } & \multicolumn{2}{|c|}{ Indústria } & \multicolumn{2}{|c|}{ Serviços } \\
\hline & Planejado & Ofertado & Planejado & Ofertado & $\begin{array}{l}\text { Plane- } \\
\text { jado }\end{array}$ & Ofertado \\
\hline Ambiente e Saúde & & & & & 03 & 08 \\
\hline $\begin{array}{l}\text { Controle e Processos } \\
\text { Industriais }\end{array}$ & & & 06 & 06 & & \\
\hline Ensino & & & & & 18 & 11 \\
\hline Gestão e Negócios & & & & & 08 & 30 \\
\hline $\begin{array}{l}\text { Informação e } \\
\text { Comunicação }\end{array}$ & & & & & 21 & 27 \\
\hline Infraestrutura & & & 10 & 10 & & \\
\hline Produção Alimentícia & & & 04 & 04 & & \\
\hline $\begin{array}{l}\text { Produção Cultural e } \\
\text { Design }\end{array}$ & & & 01 & & & \\
\hline Produção Industrial & & & 06 & 04 & & \\
\hline Recursos Naturais & 10 & 07 & & & & \\
\hline Segurança & & & & & & 07 \\
\hline $\begin{array}{l}\text { Turismo, Hospitali- } \\
\text { dade e Lazer }\end{array}$ & & & & & 07 & 08 \\
\hline Total & 10 & 07 & 27 & 24 & 57 & 91 \\
\hline$\%$ do Total & 10,6 & 5,7 & 28,7 & 19,7 & 60,7 & 74,6 \\
\hline
\end{tabular}

Fonte: PDI 2009-2013 (IFPI, 2009); PDI 2010-2014 (IFPI, 2010); Catálogo Nacional de Cursos Técnicos (BRASIL, 2013j); Catálogo Nacional de Cursos Superiores em Tecnologia (BRASIL, 2013I); Instituto Federal do Piauí (IFPI, 2013).

A área de ensino teve o espaço reduzido em relação ao planejado. Ocupava antes $31,6 \%$ dos cursos destinados ao setor de serviços, passando, na oferta, a ocupar $12,1 \%$, o que representa $9 \%$ do total de cursos ofertados. Essa área, em particular no ensino de ciências e matemática, foi apontada pelo Planap (BRASIL, 2006a-i) como deficitária em todos os territórios de desenvolvimento, inclusive como um fator limitante do desenvolvimento, que foi o objetivo estabelecido pela Lei $n$ o 11.892/2008 (BRASIL, 2008) para a expansão dos institutos.

A segunda maior fatia do setor de serviços pertence à área de informática $(22,1 \%)$; complementam o portfólio do setor as áreas de Ambiente e Saúde, e Segurança, ambas com 6,5\% do setor.

A indústria detém a segunda maior fatia da oferta de cursos, todavia, essa fatia é menor do que o planejado em três cursos (11,1\%), reduzindo-se de $28,1 \%$ a 19,7\%. Essa oferta volta-se para o setor que detém a segunda maior fatia na economia 
local e regional. Entre os municípios contemplados com a instalação de um campus, Uruçuí tem, na indústria, o principal setor da economia local (44,4\%), já nos demais, esse é o segundo setor, variando de 10,2\%, em Corrente, a 21,7\%, em Teresina.

No setor da indústria, a indústria de transformação e a indústria do agronegócio são apontadas pelo Planap (BRASIL, 2006a-i) e PDIs (IFPI, 2009; IFPI, 2010) como atividades potenciais, consolidadas e em expansão. Tem-se, como exemplo das atividades industriais, entre outras, a agroindústria de processamento de algodão, de sucos, de doces, de farinha e goma de mandioca, de mel, a agroindústria da cera de carnaúba, de base extrativista, em Sussuapara, a indústria de cimento, em Fronteiras, e de vermiculita, em Queimada Nova, no Território do Vale do Guaribas; a agroindústria de beneficiamento de arroz, milho e farinha, da produção artesanal da cachaça, cajuína e doce caseiro, do processamento de polpa de frutas, do beneficiamento da castanha de caju, da usina sucroalcooleira e do matadouro industrial de frango, no Território do Entre Rios; e a indústria secadora e esmagadora de soja, a indústria de transformação da cana-de-açúcar em álcool, a indústria de beneficiamento e empacotamento de arroz, a produção de doces e licores, a produção de farinha (em nível industrial e artesanal), e a produção de cachaça e rapadura, no Território Tabuleiros do Alto Parnaíba.

O eixo Produção Alimentícia teve o planejado efetivado, detendo $16,7 \%$ dos cursos voltados para a indústria e $3,8 \%$ do total dos cursos.

A área da Construção Civil foi contemplada com 41,7\% dos cursos voltados para o setor industrial, possuindo, desse modo, o maior espaço, tendo sido implementado o planejado.

O eixo de Controle e Processos Industriais manteve o planejado na oferta, ocupando $25 \%$ do total de cursos ofertados voltados para a indústria. Vale ressaltar que o curso de eletrotécnica pode, também, voltar-se para o setor de serviços.

O eixo Produção Industrial detém 16,7\% dos cursos ofertados no setor da indústria, embora com valores percentuais $(22,2 \%)$ e quantitativos (menos dois cursos) inferiores ao planejado. Os cursos planejados desse eixo são os de vestuário e biocombustíveis. O primeiro volta-se para importante segmento da indústria, segundo o Planap (BRASIL, 2006a-i) e PDIs (IFPI, 2009; IFPI, 2010), o de confecções de pequeno, médio e grande porte; o segundo foi suprimido da oferta.

À agropecuária, setor primário da economia, restou a menor fatia dos cursos. A fatia de $10,6 \%$ do total de cursos passou a ser $5,7 \%$. São três cursos a menos do que o planejado, uma redução de $30 \%$. Esse é o setor com menor participação na economia local e regional, variando o percentual de participação do valor adicionado bruto a preços correntes, nos municípios contemplados com a instalação de um campus, entre 0,6\%, em Teresina, e 14,2\%, em Uruçuí. 
Contudo, o setor da agropecuária é apontado pelo Plano de Ação para o Desenvolvimento Integrado da Bacia do Parnaíba - Planap (BRASIL, 2006a-i) e PDIs (IFPI, 2009; IFPI, 2010) como aquele que possui, em todos os territórios de desenvolvimento, as maiores potencialidades produtivas consolidadas e em expansão, essas, inclusive, com grande capacidade de geração e distribuição de renda e de inclusão social. A ovinocaprinocultura, a bovinocultura, o cultivo do arroz, milho, feijão (cultivo de sequeiro), a apicultura, a piscicultura, a cajucultura e a agricultura empresarial da soja são exemplos das atividades produtivas apontadas como potenciais e estratégicas. Cursos voltados para esse setor são ofertados, apenas, nos campi de Uruçuí (Agropecuária) e Corrente (Agronegócio).

Em síntese, verifica-se que $66 \%$ dos cursos planejados foram implementados, importando, portanto, numa variação de $34 \%$ do planejado e um acréscimo de 27,1\%; que as modalidades de educação a distância e técnico subsequente são as que ocupam o maior espaço na oferta de cursos dos campi instalados; que os eixos tecnológicos de Gestão e Negócios e de Informação e Comunicação detêm as maiores fatias na oferta de cursos; que o setor de serviços, seguido do industrial, é o que foi contemplado com o maior número de cursos; e que setores apontados pelo Planap (BRASIL, 2006a-i) e PDIs (IFPI, 2009; IFPI, 2010), como potenciais e estratégicos para o desenvolvimento piauiense, sobretudo na agropecuária, tiveram reduzida oferta de cursos.

Portanto, pode-se afirmar que os cursos planejados ou ofertados, ainda que se voltassem para os setores da economia estadual e local predominantes, e estivessem vinculados às metas do Plano de Desenvolvimento da Educação e aos arranjos produtivos locais, não se voltavam para os setores apontados como potenciais e estratégicos para o desenvolvimento socioeconômico, como preconizado.

\section{Considerações finais}

Entre os municípios contemplados, há aqueles que estão entre os mais populosos e de maiores economias do estado, como os de Teresina, Parnaíba, Picos e Piripiri. Os demais, à exceção de Angical do Piauí, que ocupa posição intermediária, situam-se também em posição de destaque no estado quanto à economia e ao contingente populacional. Estão distribuídos por três das quatro mesorregiões do estado (Centro-Norte Piauiense, Sudeste Piauiense e Sudoeste Piauiense) e são, na classificação do IBGE, Centro Regional A (Teresina), Centro Sub-Regional A (Parnaíba e Picos), Centro Sub-Regional B (São Raimundo Nonato), Centros de Zona A (Corrente e Piripiri), Centros de Zona B (Paulistana e Uruçuí) e Centro Local (Angical do Piauí).

Os campi estão distribuídos de forma equilibrada pelo território, favorecendo a interiorização da oferta de educação profissional, em especial de nível médio, 
em áreas carentes dessa oferta, e o acesso ao ensino médio, como deseja a lei que institui a rede, podendo, por conseguinte, contribuir para redução dos fluxos migratórios. Contudo, nem todos gozam da condição de cidade-polo, como por exemplo, o município de Angical do Piauí, que, conforme a classificação do IBGE, não dispõe da condição de centro de gestão do território, e portanto não constitui polo que possua efeito centralizador.

A oferta formativa volta-se, em sua maior parte, para a profissionalização em nível médio, correspondendo a $89 \%$ do total, o que significa que se direciona para o mercado de trabalho e para a economia local e regional, contribuindo para o funcionamento dos mesmos com formação profissional e geração de tecnologias necessárias à produção. A educação superior, por seu turno, volta-se, na sua maior parte, para o ensino nas áreas de ciências e matemática. A concentração da oferta de ensino nessas áreas atende à disposição da Lei $n$ 오 11.892/2008, que estabelece a priorização das mesmas. Contudo, a formação superior em tecnologia tem oferta de cursos reduzida.

A oferta de profissionalização em nível médio consiste em 72 cursos, distribuídos, conforme a classificação do Catálogo Nacional de Cursos Técnicos (BRASIL, 2013j) e Catálogo Nacional de Cursos Superiores de Tecnologia (BRASIL, 2013I), em dez eixos tecnológicos. Esses se voltam para os setores da agropecuária, da indústria e de serviços da economia local dos municípios contemplados e daqueles sob sua área de influência; abrangendo, ora em parte, ora na sua totalidade, os territórios de desenvolvimento aos quais pertencem. Contudo, apenas o setor de serviços possui cursos ofertados em todos os campi. A indústria tem cursos em três campi e a agropecuária em apenas dois.

O quantitativo de cursos que coube a cada um dos setores da economia acompanha a participação do valor adicionado bruto a preços correntes dos referidos setores em todos os municípios com campus instalado, à exceção do município de Uruçuí, onde se verifica uma inversão entre o setor de serviços e o da indústria.

Há atividades produtivas potenciais que foram contempladas com formações voltadas a elas mesmas, como as do turismo, serviços públicos, comércio, eventos e da indústria de alimentos. Contudo, são várias as atividades potenciais, consolidadas e em expansão, às quais não foi destinada oferta de cursos, sobretudo em setores da agropecuária (como a apicultura, cajucultura, ovinocaprinocultura, mandiocultura e piscicultura) que seriam possuidores de grande capacidade de geração e distribuição de renda, e de inclusão social.

Desse modo, a contribuição da oferta educacional, ainda que esteja articulada à expectativa dos setores com maior participação na economia, não atende a todos os referenciais do Plano de Ação para o Desenvolvimento Integrado da Bacia do Parnaíba, que identifica as atividades produtivas potencialmente capazes de transformar as condições socioeconômicas. 
A análise da expansão da Rede Federal de Educação, Ciência e Tecnologia no Estado do Piauí, aqui empreendida, diz respeito à questão da adequação da implementação da política ao marco normativo de intenções posto nos documentos e regulamentos governamentais, por consequência, ao raio de discricionariedade comum à fase de implementação, no qual as escolhas feitas têm desdobramentos nos efeitos pretendidos, quando da formulação. Verificou-se que as escolhas realizadas, em alguns momentos, distanciaram-se do marco normativo, embora não colidindo na totalidade com o mesmo; em outros momentos, aproximam-se dele, demonstrando a persecução do implementador às diretrizes postas.

Embora não se pretenda esgotar a discussão neste trabalho, as reflexões desenvolvidas quanto à adequação das escolhas, seja dos municípios contemplados com a instalação de um campus, seja dos cursos ofertados, e quanto às diretrizes impostas à política, encerram um exame de pertinência e adequação quanto à utilização da educação profissional e tecnológica como integrante de estratégias governamentais de desenvolvimento econômico-social. A interiorização e articulação da oferta aos arranjos produtivos locais põem em curso uma aproximação cada vez maior entre a educação e o sistema produtivo, em que a primeira é funcional, prestando seus serviços ao segundo.

\section{Referências bibliográficas}

BRASIL. Companhia de Desenvolvimento dos Vales do São Francisco e do Parnaíba Codevasf. Plano de Ação para o Desenvolvimento Integrado da Bacia do Parnaíba, Planap: Síntese Executiva: Território da Planície Litorânea. Brasília, DF: TDA Desenhos \& Arte Ltda, 2006a.

Companhia de Desenvolvimento dos Vales do São Francisco e do Parnaíba - Codevasf. Plano de Ação para o Desenvolvimento Integrado da Bacia do Parnaíba, Planap: Síntese Executiva: Território dos Cocais. Brasília, DF: TDA Desenhos \& Arte Ltda, 2006b.

Companhia de Desenvolvimento dos Vales do São Francisco e do Parnaíba - Codevasf. Plano de Ação para o Desenvolvimento Integrado da Bacia do Parnaíba, Planap: Síntese Executiva: Território dos Carnaubais. Brasília, DF: TDA Desenhos \& Arte Ltda, 2006c.

Companhia de Desenvolvimento dos Vales do São Francisco e do

Parnaíba - Codevasf. Plano de Ação para o Desenvolvimento Integrado da Bacia do Parnaíba, Planap: Síntese Executiva: Território Entre Rios. Brasília, DF: TDA Desenhos \& Arte Ltda, 2006d.

Companhia de Desenvolvimento dos Vales do São Francisco e do Parnaíba - Codevasf. Plano de Ação para o Desenvolvimento Integrado da Bacia 
do Parnaíba, Planap: Síntese Executiva: Território Vale do Rio Guaribas. Brasília, DF: TDA Desenhos \& Arte Ltda, 2006e.

Companhia de Desenvolvimento dos Vales do São Francisco e do Parnaíba - Codevasf. Plano de Ação para o Desenvolvimento Integrado da Bacia do Parnaíba, Planap: Síntese Executiva: Território Serra da Capivara. Brasília, DF: TDA Desenhos \& Arte Ltda, $2006 \mathrm{f}$.

Companhia de Desenvolvimento dos Vales do São Francisco e do Parnaíba - Codevasf. Plano de Ação para o Desenvolvimento Integrado da Bacia do Parnaíba, Planap: Síntese Executiva: Território Tabuleiros do Alto Parnaíba. Brasília, DF: TDA Desenhos \& Arte Ltda, 2006g.

Companhia de Desenvolvimento dos Vales do São Francisco e do Parnaíba - Codevasf. Plano de Ação para o Desenvolvimento Integrado da Bacia do Parnaíba, Planap: Síntese Executiva: Território Chapada das Mangabeiras. Brasília, DF: TDA Desenhos \& Arte Ltda, 2006h.

Companhia de Desenvolvimento dos Vales do São Francisco e do Parnaíba - Codevasf. Plano de Ação para o Desenvolvimento Integrado da Bacia do Parnaíba, Planap: Síntese Executiva: Território da Planície Litorânea. Brasília, DF: TDA Desenhos \& Arte Ltda, 2006i.

Ministério da Educação. Secretaria de Educação Profissional e Tecnológica. Plano de Expansão da Rede Federal de Educação Tecnológica. Brasília, 2006j. Disponível em: <http://portal.mec.gov.br/setec/arquivos/pdf/expansao_ plano.pdf>. Acesso em: 11 jan. 2013.

Ministério do Planejamento, Orçamento e Gestão. Secretaria de Planejamento e Investimentos Estratégicos. Plano Plurianual 2008-2011: projeto de lei. Brasília, 2007a.

Ministério da Educação. Secretaria de Educação Profissional e Tecnológica. Chamada Pública MEC/Setec no 001/2007. Brasília, 2007b. Disponível em: <http://portal.mec.gov.br/setec/arquivos/pdf/edital_chamadapublica_fase2.pdf>. Acesso em: 11 jan. 2013.

Ministério da Educação. Plano de Desenvolvimento da Educação. Brasília, 2007c. Disponível em: < http://portal.mec.gov.br/arquivos/livro/index.htm>. Acesso em: 05 nov. 2010.

Lei no 11.892, de 29/12/2008. Institui a Rede de Educação Profissional, Científica e Tecnológica, cria os institutos federais de educação, ciência e tecnologia, e dá outras providências. Brasília, 2008. Disponível em:<http://planalto.gov.br/ ccivil_03/_ato2007-2010/2008/lei/l11892.htm>. Acesso em 18 fev. 2013. 
Ministério da Educação. Indicadores Demográficos e Educacionais: Estado do Piauí, Município de Picos. Brasília, 2013a. Disponível em: < http://ide. mec.gov.br/2011/municipios/relatorio/coibge/2208007>. Acesso em: 05 fev. 2013.

Ministério da Educação. Indicadores Demográficos e Educacionais: Estado do Piauí, Município de Parnaíba. Brasília, 2013b. Disponível em: < http://ide. mec.gov.br/2011/municipios/relatorio/coibge/2207702>. Acesso em: 05 fev. 2013.

Ministério da Educação. Indicadores Demográficos e Educacionais: Estado do Piauí, Município de Uruçuí. Brasília, 2013c. Disponível em: < http://ide. mec.gov.br/2011/municipios/relatorio/coibge/2211209>. Acesso em: 05 fev. 2013.

Ministério da Educação. Indicadores Demográficos e Educacionais: Estado do Piauí, Município de Teresina. Brasília, 2013d. Disponível em: <http://ide. mec.gov.br/2011/municipios/relatorio/coibge/2211001>. Acesso em: 05 fev. 2013.

Ministério da Educação. Indicadores Demográficos e Educacionais: Estado do Piauí, Município de Corrente. Brasília, 2013e. Disponível em: < http://ide. mec.gov.br/2011/municipios/relatorio/coibge/2202901>. Acesso em: 05 fev. 2013.

Ministério da Educação. Indicadores Demográficos e Educacionais: Estado do Piauí, Município de São Raimundo Nonato. Brasília, 2013f. Disponível em: <http://ide.mec.gov.br/2011/municipios/relatorio/coibge/2210607>. Acesso em: 05 fev. 2013.

Ministério da Educação. Indicadores Demográficos e Educacionais: Estado do Piauí, Município de Piripiri. Brasília, 2013g. Disponível em: < http://ide. mec.gov.br/2011/municipios/relatorio/coibge/2208403>. Acesso em: 05 fev. 2013.

Ministério da Educação. Indicadores Demográficos e Educacionais: Estado do Piauí, Município de Paulistana. Brasília, 2013h. Disponível em: < http://ide. mec.gov.br/2011/municipios/relatorio/coibge/2207801>. Acesso em: 05 fev. 2013.

Ministério da Educação. Indicadores Demográficos e Educacionais: Estado do Piauí, Município de Angical do Piauí. Brasília, 2013i. Disponível em: < http://ide.mec.gov.br/2011/municipios/relatorio/coibge/2200608>. Acesso em: 05 fev. 2013.

Ministério da Educação. Catálogo Nacional de Cursos Técnicos. Brasília, 2013j. Disponível em: <http://pronatec.mec.gov.br/cnct/eixos_tecnologicos.php>. Acesso em: 10 jan. 2013.

Ministério da Educação. Catálogo Nacional dos Cursos Superiores de Tecnologia. Brasília, 2013l. Disponível em: <http://portal.mec.gov.br/index. php? |temid=86\&id=12352\&option=com_content\&view=article $>$. Acesso em: 10 jan. 2013.

Ministério da Educação. Exame Nacional do Ensino Médio. Brasília, 2013m. Disponível em: <http://noticias.terra.com.br/educacao/enem/mec-divulga- 
resultado-do-enem-2011-por-escola-veja-lista,c638e1f20735b310VgnCLD200000bbc ceb0aRCRD.html> Acesso em: 25 fev. 2013.

InStituto BRAsileiro de Geografia e Estatística (IBGE). Regiões de Influência das Cidades 2007. Rio de Janeiro: Centro de Documentação e Disseminação de Informações, 2008.

Censo Demográfico 2010. Rio de Janeiro, 2010. Disponível em: <TTP:// cidades.ibge.gov.br/xtras/perfil.php?lang=\&codmun=220005\&search=piaui $>$. Acesso em: 10 fev. 2013.

Mesorregião. Rio de Janeiro, 2013. Disponível em: <TTP://www.ibge. gov.br/home/geociencias/geografia/default_div_int.shtm>. Acesso em: 10 fev. 2013. Instituto Federal de Educação, Ciência e TeCnologia do Piauí (IFPI). Plano de Desenvolvimento Institucional-PDI 2009-2013. Teresina: Editora, 2009.

Plano de Desenvolvimento Institucional (PDI) 2010-2014. Teresina: Editora, 2010.

Cursos. Teresina, 2013. Disponível em; <http://www5.ifpi.edu.br/> Acesso em: 02 jan. 2013.

instituto nacional de Estudos e Pesquisas Educacionais Anísio Teixeira (INEP). Sinopse Estatística da Educação Básica - 2010. Brasília, 2011. Disponível em: <http://portal.inep.gov.br/basica-censo-escolar-sinopse-sinopse> Acesso em: 28 mar. 2013.

Piauí. Secretaria de Planejamento. Lei Complementar no 87, de 22/08/2007. Estabelece o Planejamento Participativo Territorial para o Desenvolvimento Sustentável do Estado do Piauí e dá outras providências. Teresina, 2007. Disponível em: <http://www.seplan.pi.gov.br/uapr/projetoCenariosRegionaisPiaui.PDF>. Acesso em: 05 jan. 2013.

PEREIRA, Samara Cristina Silva. A política de educação profissional média integrada: entre o legal e o real.14/08/2012. 136 p. Dissertação de mestrado em Políticas Públicas - Universidade Federal do Piauí. Teresina, 2012.

SERAFIM, M. P.; DIAS, R. de B. Conceitos e ferramentas para análise de política pública. In: BENINI, Édi. et al. (Org.). Gestão social e gestão pública: interfaces, delimitações e uma proposta. Gestão Pública e sociedades: fundamentos e políticas de economia solidária. 1 ed. São Paulo: Outras Expressões, 2011, p. 305 - 338.

Silva, Pedro Luiz Barros ; Melo, Marcus André. O processo de implementação de políticas públicas no Brasil: características e determinantes da avaliação de programas e projetos. Campinas: Núcleo de Estudos de Políticas Públicas - UNICAMP. Caderno de Pesquisa, no 48, outubro 2000. Disponível em: <http://governancaegestao.files. wordpress.com/2008/05/teresa-aula_22.pdf>. Acesso em: 21 jan. 2013. 
José Tavares da Silva Neto

Mestre em Políticas Públicas pela Universidade Federal do Piauí (UFPI) e Especialista em Gestão de Materiais e Patrimônio no Setor Público pela Universidade Gama Filho (UGF). Analista de Planejamento, Gestão e Infraestrutra, especialidade Gestão e Infraestrutura do Instituto Brasileiro de Geografia e Estatística (IBGE). Contato: jose-silva.neto@ibge.gov.br

Guiomar de Oliveira Passos

Doutora em Sociologia pela Universidade de Brasília (UnB) e Professora Associada da Universidade Federal do Piauí (UFPI).Contato: guiomar@ufpi.edu.br 
RSP 